\title{
Microstructure refinement and grain size distribution in crack initiation region of very-high-cycle fatigue regime for high-strength alloys
}

\author{
Yukun Chang ${ }^{\mathrm{a}, \mathrm{c}}$, Xiangnan Pan ${ }^{\mathrm{a}, \mathrm{b}}$, Liang Zheng ${ }^{\mathrm{c}, *}$, Youshi Hong ${ }^{\mathrm{a}, \mathrm{b}, *}$ \\ ${ }^{a}$ LNM, Institute of Mechanics, Chinese Academy of Sciences, Beijing 100190, China \\ ${ }^{\mathrm{b}}$ School of Engineering Science, University of Chinese Academy of Sciences, Beijing 100049, China \\ ${ }^{\mathrm{c}}$ School of Science, Harbin Institute of Technology, Shenzhen 518055, China
}

\section{A R T I C L E I N F O}

\section{Keywords:}

Very-high-cycle fatigue

Crack initiation

Fine granular area (FGA)

Rough area (RA)

High-strength alloys

\begin{abstract}
A B S T R A C T
The microstructural features underneath the fracture surfaces of high-strength alloys experienced very-highcycle fatigue were further investigated to show the nanograin layer in crack initiation regions under negative stress ratios due to numerous cyclic pressing (NCP) mechanism. The grain size and the thickness of nanograin layer in fine granular area of high-strength steels and rough area of titanium alloys were measured. A normalized quantity $d^{*}$ was proposed to characterize the distribution of the nanograin size. A new schematic to express NCP process was depicted to describe the contacting actions between crack surfaces, which causes the microstructure refinement of the high-strength alloys.
\end{abstract}

\section{Introduction}

In recent decades, many engineering structures and components in transportation industry, such as aircrafts, automobiles, high-speed trains, etc., require not only high strength but also high fatigue resistance to ensure their long-term safety and stability. Therefore, veryhigh-cycle fatigue (VHCF, i.e., failure cycles beyond $10^{7}$ ) behavior of metallic materials has become an important topic in structural integrity $[1,2]$. Researchers have paid considerable attention to VHCF investigations of metallic materials, due to its specific mode of crack initiation and fractographic features, which marks the emergence of the new fatigue research area [3-5]. The behavior in VHCF of many highstrength alloys, such as high-strength steels and titanium alloys, becomes more attractive owing to their wide engineering applications.

It has been known that for high-strength steels in VHCF regime, cracks are prone to initiate from the subsurface at interior defects (commonly inclusions) of a specimen. A relatively rough region named fine granular area (FGA) is presented around the inclusion, and the FGA region is surrounded by a flat fish-eye (FiE) region [6-10]. The unique fractographic feature has attracted the interests of many researchers. Nakamura et al. [11] conducted fatigue crack growth tests for a Ni-CrMo steel in a high vacuum environment to monitor subsurface crack propagation and predicted that the crack growth rate is lower than $10^{-11} \mathrm{~m} /$ cycle in FGA region. Ogawa et al. [12] performed "two-step" and "repeated two-step" loading tests for an SUJ2 steel and extrapolated the value of $\mathrm{d} a / \mathrm{d} N$ to be between $10^{-13}$ and $10^{-14} \mathrm{~m} /$ cycle in the FGA region by the detected beach marks in the FiE region. Hong et al [13] also estimated from the tested data that the value of $\mathrm{d} a$ / $\mathrm{d} N$ is between $10^{-12}$ and $10^{-13} \mathrm{~m} /$ cycle in the FGA region for a highstrength steel. Recently, Hu et al. [14] first captured the crack growth traces in the FGA region under repeated two-step cycling for a high carbon chromium steel and obtained the crack growth rate in the FGA region ranging from $10^{-11}$ to $10^{-13} \mathrm{~m} /$ cycle. The above results showed that the crack growth rate is much lower than the lattice spacing $\left(10^{-10}\right.$ $\mathrm{m}$ ), suggesting that the process of crack growth in the FGA region should be greatly influenced by the related microstructure. For this, Zhao et al. [15] assumed that the process of crack initiation ends when the plastic zone size at the crack tip equals to the characteristic size of the material and proposed a model to calculate the range of stress intensity factor at the periphery of FGA. The obtained values are very close to the threshold values for the growth of long fatigue cracks and also matched well with the experimental results reported in the literature $[7,8,15-18]$. Therefore, FGA is regarded as the characteristic region of the internal crack initiation for high-strength steels in VHCF regime [13]. Moreover, many prediction results showed that FGA region consumes the majority of total fatigue life $[13,19,20]$. When the total fatigue life is beyond $5 \times 10^{7}$ cycles, the life consumed in FGA is even larger than $99 \%$ [13].

Different from high-strength steels that usually contain microstructural defects like inclusions, titanium alloys (e.g. Ti-6Al-4V) are

\footnotetext{
* Corresponding authors at: Institute of Mechanics, Chinese Academy of Sciences, Beijing 100190, China (Y. Hong).

E-mail addresses: icon_lzheng@hit.edu.cn (L. Zheng), hongys@imech.ac.cn (Y. Hong).
} 
Table 1

Chemical composition (wt\%) of tested high-strength steels.

\begin{tabular}{llllllll}
\hline Material & C & Cr & Mn & Si & S & P & Fe \\
\hline A & 1.06 & 1.04 & 0.88 & 0.34 & 0.005 & 0.027 & Bal. \\
B & 1.04 & 1.51 & 0.29 & 0.24 & 0.003 & 0.0058 & Bal. \\
\hline
\end{tabular}

Table 2

Chemical composition (wt\%) of tested titanium alloys.

\begin{tabular}{llllllll}
\hline Material & $\mathrm{Al}$ & $\mathrm{V}$ & $\mathrm{Fe}$ & $\mathrm{N}$ & $\mathrm{C}$ & $\mathrm{O}$ & $\mathrm{Ti}$ \\
\hline $\mathrm{D}$ & 5.8 & 4.2 & 0.12 & 0.03 & 0.02 & 0.15 & Bal. \\
$\mathrm{E}$ & 5.96 & 4.13 & 0.16 & 0.015 & 0.02 & 0.18 & Bal. \\
\hline
\end{tabular}

almost free of inclusions and voids. The microstructure of a titanium alloy depends on the volume fraction and the shape of $\alpha$ phase and $\beta$ phase, in which $\alpha$ phase is of a hexagonal close-packed structure and $\beta$ phase a body-centered cubic structure. Based on the experienced heattreatment and manufacturing process, titanium alloys may have four types of microstructure, i.e. the type of duplex, equiaxed, lamellar and basket weave. In VHCF of titanium alloys, most of cracks initiate from the cleavage of $\alpha$ phase to form facet morphology [21-24], and then the coalescence of distributed facets forms a rough area (RA) on the fracture surface. Similar to the FGA in high-strength steels, the range of stress intensity factor in RA for titanium alloys is close to the threshold value for the growth of long fatigue cracks, and most of the fatigue life is consumed in RA. Thus RA is also regarded as the characteristic region of the crack initiation in VHCF regime for titanium alloys [25].

Due to the important roles of FGA and RA in VHCF regime of metallic materials, the formation mechanism of FGA and RA has been widely investigated in the past two decades, and several investigations have focused on the microstructure characteristics with relation to crack initiation in the FGA region. Sakai [26] examined the microstructure beneath FGA by transmission electron microscopy (TEM), and

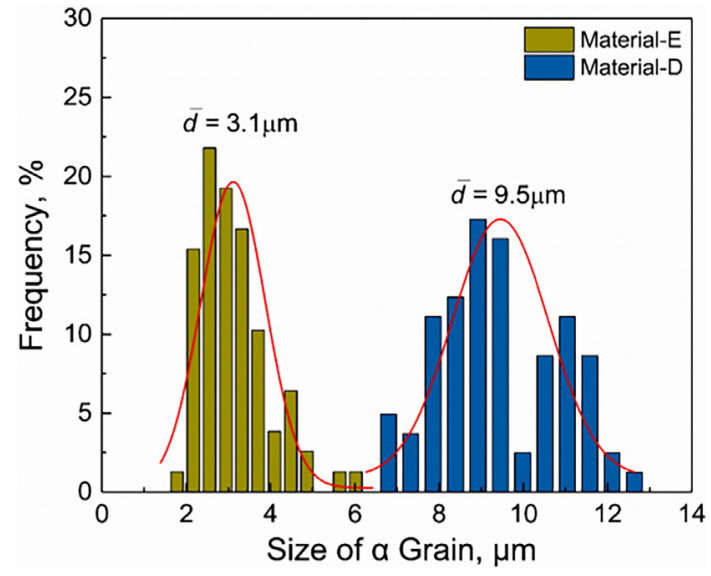

Fig. 2. Size distribution of $\alpha$ grains for two titanium alloys D and E.

showed that a fine granular layer presents inside the FGA, whereas the fine polygonization disappears in the location away from the FGA. Similarly, Grad et al. [27] reported that an average grain size of about $70 \mathrm{~nm}$ exists in the FGA for a high-strength steel and proposed an FGA formation mechanism called "local grain refinement at the crack tip", which was similar to the previously proposed model [26], and was further extended recently by Spriestersbach et al. [28]. Kovacs et al [29] examined failed VHCF specimens of a martensitic steel and reported that a nanocrystalline layer with the thickness of about $3 \mu \mathrm{m}$ underneath the fracture surface formed during the fatigue test at $R=-1$, whereas no fine grained area was detected at $R=0.1$. With regard to Ti-6Al-4V alloys, Oguma et al. [30] noticed the existence of fine concave-convex particles on the fracture surfaces in a vacuum environment and presumed that the metal-metal contacts may occur during the unloading process, causing cold-welding at the fracture surfaces to form RA for titanium alloys. However, the microstructure details at the crack initiation region, i.e. FGA region of high-strength
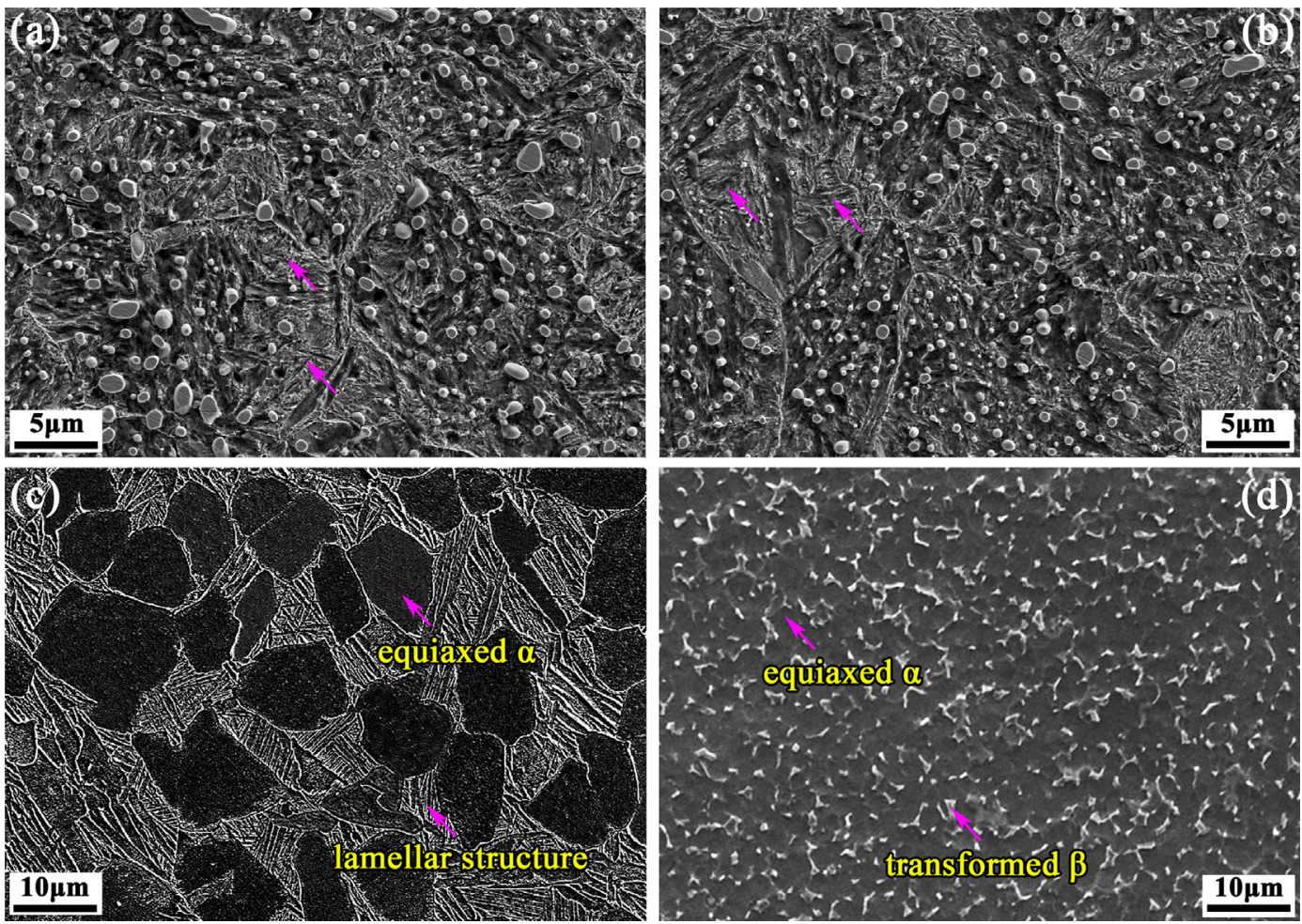

Fig. 1. SEM images showing tempered martensite for material A (a) and material B (b); SEM images showing duplex microstructure for material D (c) and equiaxed microstructure for material E (d). 
Table 3

Loading conditions and sampling locations for TEM samples.

\begin{tabular}{|c|c|c|c|c|c|c|}
\hline Specimen & Loading & $\sigma_{\mathrm{a}} / \mathrm{MPa}$ & $\sigma_{\max } / \mathrm{MPa}$ & $\sigma_{\min } / \mathrm{MPa}$ & $N_{\mathrm{f}} /$ cycles & Sampling location \\
\hline A1 & $\mathrm{RB}, R=-1$ & 775 & 775 & -775 & $2.40 \times 10^{7}$ & FGA \\
\hline A2 & $\mathrm{RB}, R=-1$ & 750 & 750 & -750 & $5.08 \times 10^{7}$ & FiE \\
\hline B1 & $\mathrm{UL}, R=-1$ & 989 & 989 & -989 & $1.11 \times 10^{8}$ & FGA \\
\hline B2 & $\mathrm{UL}, R=-0.5$ & 633 & 844 & -422 & $4.81 \times 10^{8}$ & FGA \\
\hline B3 & $\mathrm{UL}, R=0.1$ & 534 & 1187 & 119 & $1.84 \times 10^{7}$ & CIR \\
\hline B4 & $\mathrm{UL}, R=0.3$ & 422 & 1206 & 362 & $9.76 \times 10^{7}$ & CIR \\
\hline B5 & $\mathrm{UL}, R=0.3$ & 430 & 1229 & 368 & $8.70 \times 10^{8}$ & FiE \\
\hline D1 & $\mathrm{UL}, R=-1$ & 550 & 550 & 550 & $4.52 \times 10^{7}$ & RA \\
\hline $\mathrm{D} 2$ & $\mathrm{UL}, R=-1$ & 450 & 450 & 450 & $1.79 \times 10^{9}$ & RA \\
\hline D3 & $\mathrm{UL}, R=0.5$ & 240 & 960 & 480 & $4.30 \times 10^{7}$ & RA \\
\hline E1 & UL, $R=-1$ & 444 & 444 & 444 & $1.06 \times 10^{8}$ & RA \\
\hline $\mathrm{E} 2$ & $\mathrm{UL}, R=-1$ & 434 & 434 & 434 & $4.51 \times 10^{8}$ & RA \\
\hline E3 & $\mathrm{UL}, R=0.5$ & 148 & 592 & 296 & $1.68 \times 10^{8}$ & RA \\
\hline
\end{tabular}
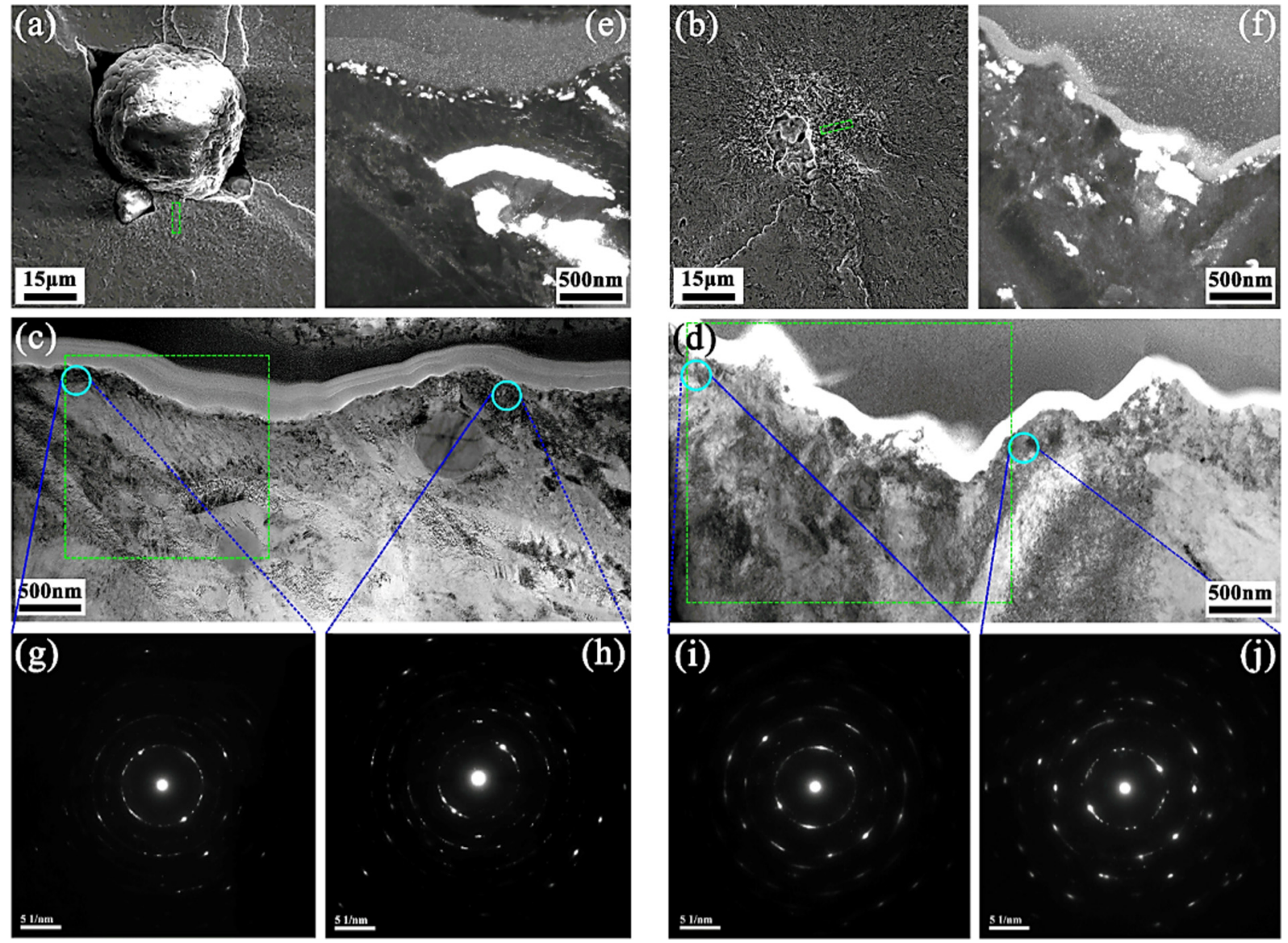

Fig. 3. Observations of high-strength steel samples A1 and B2. SEM images showing fracture surface morphology: (a) A1 $\left(R=-1, \sigma_{\mathrm{a}}=775 \mathrm{MPa}, N_{\mathrm{f}}=2.40 \times 10^{7}\right)$ and (b) B2 $\left(R=-0.5, \sigma_{\mathrm{a}}=633 \mathrm{MPa}, N_{\mathrm{f}}=4.81 \times 10^{8}\right)$, dashed rectangle representing sampling location; BFIs showing microstructure underneath FGA region of (c) A1 and (d) B2; (e, f) DFIs showing microstructure for dashed boxes in (c) and (d); (g-j) SAD patterns showing discontinuous diffraction circles at the location just underneath FGA surface.

steels or RA region of titanium alloys, including the thickness of refined microstructure layer and the refined grain size distribution, are still unclear.

In order to understand the formation mechanism of FGA more reasonably, Hong et al. [31] analyzed the microstructure feature in the crack initiation region (CIR) of the specimens failed under different stress ratios for high-strength steels. Their observations revealed that a nanograin layer of FGA exists under negative stress ratios, whereas the nanograin feature of FGA is diminishing or even extinguishing under positive stress ratios. Based on such experimental results, a "numerous cyclic pressing (NCP)" model was proposed to explain the formation process of FGA. Subsequent results obtained on structural steels $[14,32]$ and titanium alloys [25,33] validated the NCP model. Recent simulation results [34-36] showed the strong contact actions between crack surfaces under negative stress ratios and the prevalence of residual stresses on the accumulation of plastic strain around the inclusion, which were well-predicted by the NCP model, and again validated that the formation of nanograins is associated with the process of crack closure and residual stress relaxation. Nevertheless, the NCP model as well as other models did not concern about the microstructure details in CIR. In other words, if the detailed microstructure feature at the crack initiation of VHCF for high-strength steels and titanium alloys is clearly revealed, the previously proposed models will be further examined to show the applicability. In fact, the detailed microstructure feature in 

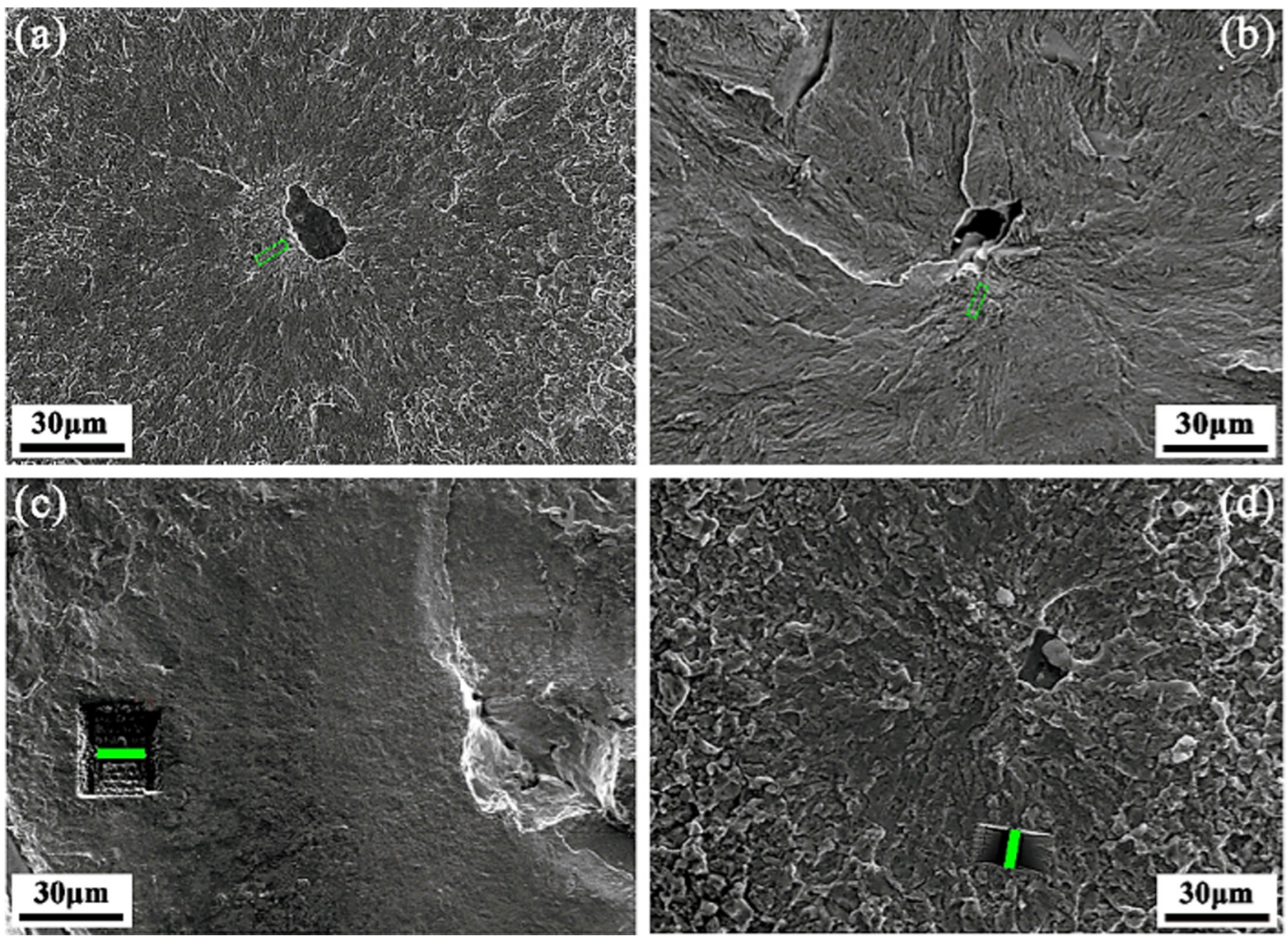

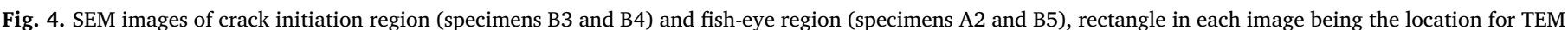

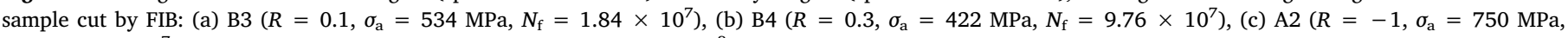
$\left.N_{\mathrm{f}}=5.08 \times 10^{7}\right)$, and (d) B5 $\left(R=0.3, \sigma_{\mathrm{a}}=430 \mathrm{MPa}, N_{\mathrm{f}}=8.70 \times 10^{8}\right)$.

CIR will provide the direct and important evidence of microstructure evolution during crack initiation process, which will help us to understand the mechanism of crack initiation for VHCF of high-strength steels and titanium alloys.

Therefore, the aim of this paper is to comprehensively investigate the microstructure refinement of CIR in VHCF regime for high-strength steels and titanium alloys. The sectional samples (TEM samples) prepared via FIB technique in CIR were carefully examined by TEM with selected area electron diffraction (SAD) detection to observe the microstructure morphology in CIR. The thicknesses of nanograin layers were measured by SAD detection from a number of TEM samples of high-strength steels and titanium alloys, and a normalized quantity $d^{*}$ based on the electron diffraction mechanism [37] was introduced to quantitatively describe the distribution of grain size along the crack path. The obtained results indicated that larger contacting actions (higher contact pressure and longer loading cycles) between crack surfaces may promote grain refinement. In addition, based on the experimental results, a new schematic of crack initiation was depicted to describe the NCP process that causes the microstructure refinement of high-strength alloys.

\section{Test materials and experimental procedures}

\subsection{Test materials}

The test materials used in this investigation are two high carbon chromium steels and two titanium alloys (Ti-6Al-4V) with duplex and equiaxed microstructures. The chemical compositions of four materials are listed in Tables 1 and 2. These four materials were marked as A, B, D and $\mathrm{E}$, in which materials $\mathrm{A}$ and $\mathrm{B}$ are high-strength steels, and materials $\mathrm{D}$ and $\mathrm{E}$ are titanium alloys.

Hour-glass shaped specimens for fatigue testing were machined from the annealed material bars. For the steel specimens, two heat- treatment procedures were performed: austenitized at $845^{\circ} \mathrm{C}$ for $2 \mathrm{~h}$ in vacuum then oil-quenched and tempered for $2 \mathrm{~h}$ in vacuum at $180{ }^{\circ} \mathrm{C}$ for material $\mathrm{A}$, and austenitized at $845{ }^{\circ} \mathrm{C}$ for $1 \mathrm{~h}$ in vacuum then oilquenched and tempered for $2 \mathrm{~h}$ in vacuum at $180{ }^{\circ} \mathrm{C}$ for material $\mathrm{B}$. After such heat-treatment processes, identical microstructures of tempered martensite were obtained for materials A and B as shown in Fig. $1 \mathrm{a}$ and $\mathrm{b}$. The tempered martensite is a mixed microstructure, consisting of plate martensite (marked by arrows in Fig. 1a and b) and spherical carbides. The average equivalent diameter of prior austenite is $13.6 \mu \mathrm{m}$ for material $\mathrm{A}$ and $13.9 \mu \mathrm{m}$ for material $\mathrm{B}$, which were obtained by the measurements of dozens of grains for each material on polished and etched samples. The average width of martensite plates is between $320 \mathrm{~nm}$ and $570 \mathrm{~nm}$ for material A and material B, which were obtained by the measurements of dozens of plates for each material on the SEM photos taken on polished and etched samples. The average equivalent carbide diameter is $0.81 \mu \mathrm{m}$ for material A and $0.89 \mu \mathrm{m}$ for material B, which were obtained by the measurements of about 100 carbides for each material on the SEM photos.

For Ti-6Al-4V alloys, the received material is of equiaxed microstructure, and Fig. 1d shows the equiaxed microstructure of material E, in which the irregular transformed $\beta$ is randomly distributed in equiaxed $\alpha$ matrix. For material $\mathrm{D}$, the specimen was heated at $920{ }^{\circ} \mathrm{C}$ for $1 \mathrm{~h}$, air-cooled, heated again at $550{ }^{\circ} \mathrm{C}$ for $4 \mathrm{~h}$, and then air-cooled to have the duplex microstructure consisting of equiaxed $\alpha$ grains and lamellar structure as shown in Fig. 1c.

Note that equiaxed $\alpha$ grains in titanium alloys always act as crack origins in VHCF failure, and the size of equiaxed $\alpha$ grains may play an important role in the fatigue damage process. Hence, the sizes of equiaxed $\alpha$ grains were measured for materials $\mathrm{D}$ and $\mathrm{E}$ as shown in Fig. 2. It is seen that the average equivalent diameter of equiaxed $\alpha$ grains for the duplex titanium alloy (material D) is $9.5 \mu \mathrm{m}$, which is three times that of the equiaxed titanium alloy (material E). The ultimate tensile strength is $1849 \mathrm{MPa}$ for material A, $1896 \mathrm{MPa}$ for material 

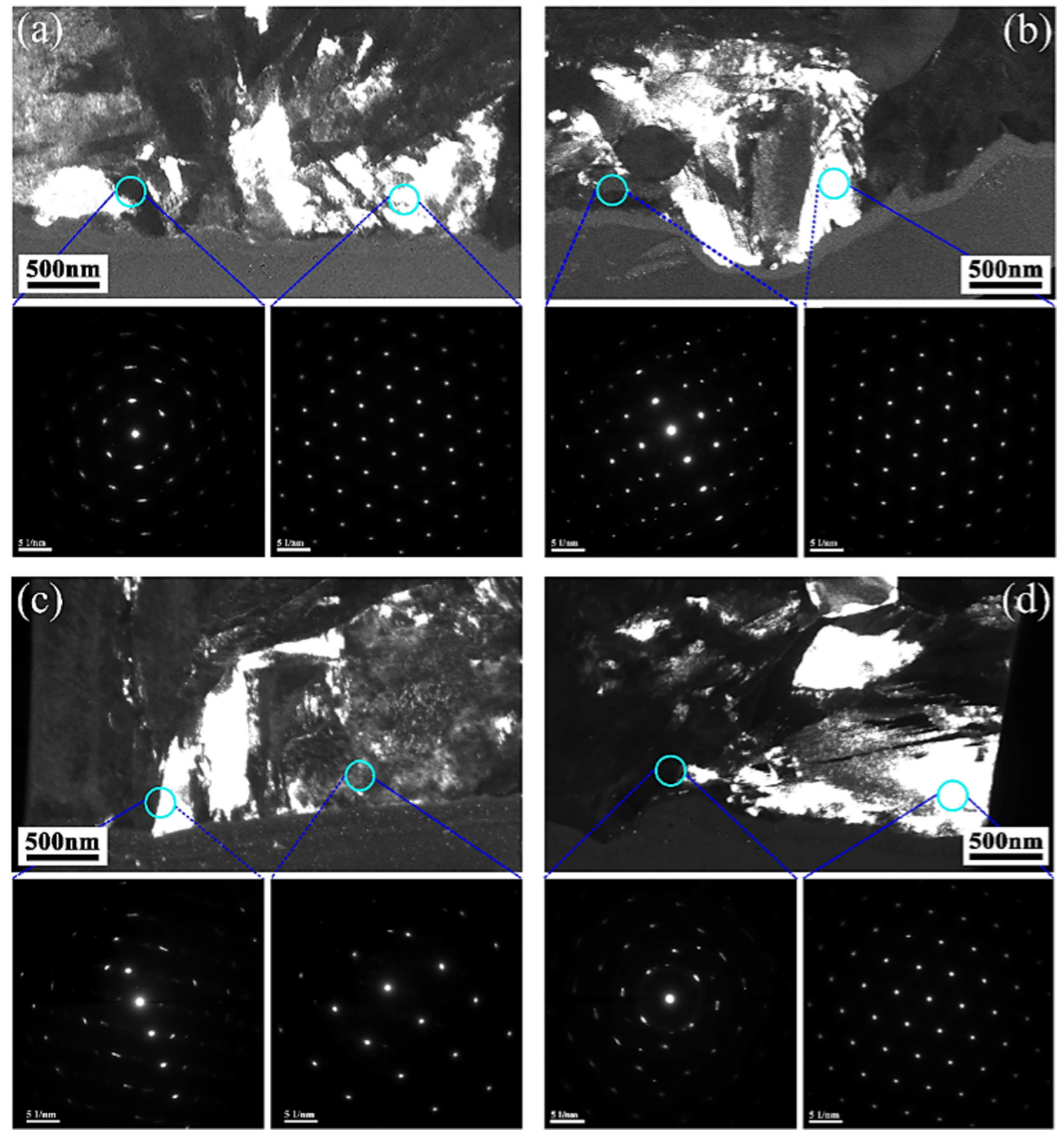

Fig. 5. TEM images and associated SAD patterns of isolated spots at the locations just underneath fracture surface: (a) sample B3, (b) sample B4, (c) sample A2, and (d) sample B5.

B, $945 \mathrm{MPa}$ for material D and $980 \mathrm{MPa}$ for material E, which were obtained by uniaxial tensile testing with cylindrical specimens at room temperature $[21,31,33]$.

\subsection{Sample preparation and TEM characterization}

Rotary bending (RB) and ultrasonic axial loading (UL) are common methods for VHCF testing. In the previous research accomplished in our group, material A was tested by RB method with $R=-1$, and materials $\mathrm{B}, \mathrm{D}$ and $\mathrm{E}$ were tested by UL method (equipped with a tensile machine to superimpose required mean stress) running at the resonant frequency of $20 \mathrm{kHz}$ with several stress ratios. After the fatigue testing, fracture surfaces of all failed specimens were observed by scanning electron microscopy (SEM). The detailed results regarding the fatigue testing and fracture surface observations were described in Refs. [21], [31] and
[33]. In the present research, 13 specimens failed in VHCF regime, including 7 of high-strength steels and 6 of titanium alloys, were selected for the preparation of TEM samples at certain positions in CIR by FIB technique. The loading conditions of the selected specimens and the related sampling locations are listed in Table 3.

In the TEM sample preparation, a Pt coating layer was deposited at the selected location to protect the fracture surface. Then, a Ga + beam was used to cut the front and rear flanks of the selected location. Next, the slice was placed on the pillar of the copper net by using a mechanical micromanipulator. Finally, the $\mathrm{Ga}+$ beam was used again to thin the sample until its thickness reduces to about $50 \mathrm{~nm}$. Such samples, each with the size of $10 \mu \mathrm{m} \times 5 \mu \mathrm{m} \times 50 \mathrm{~nm}$, were then carefully examined by TEM (FEI Tecnai G2 F30 S-TWIN), and the microstructure characteristics were detected by SAD with an aperture diameter of $200 \mathrm{~nm}$. The existence of nanocrystalline or the thickness of nanograin 

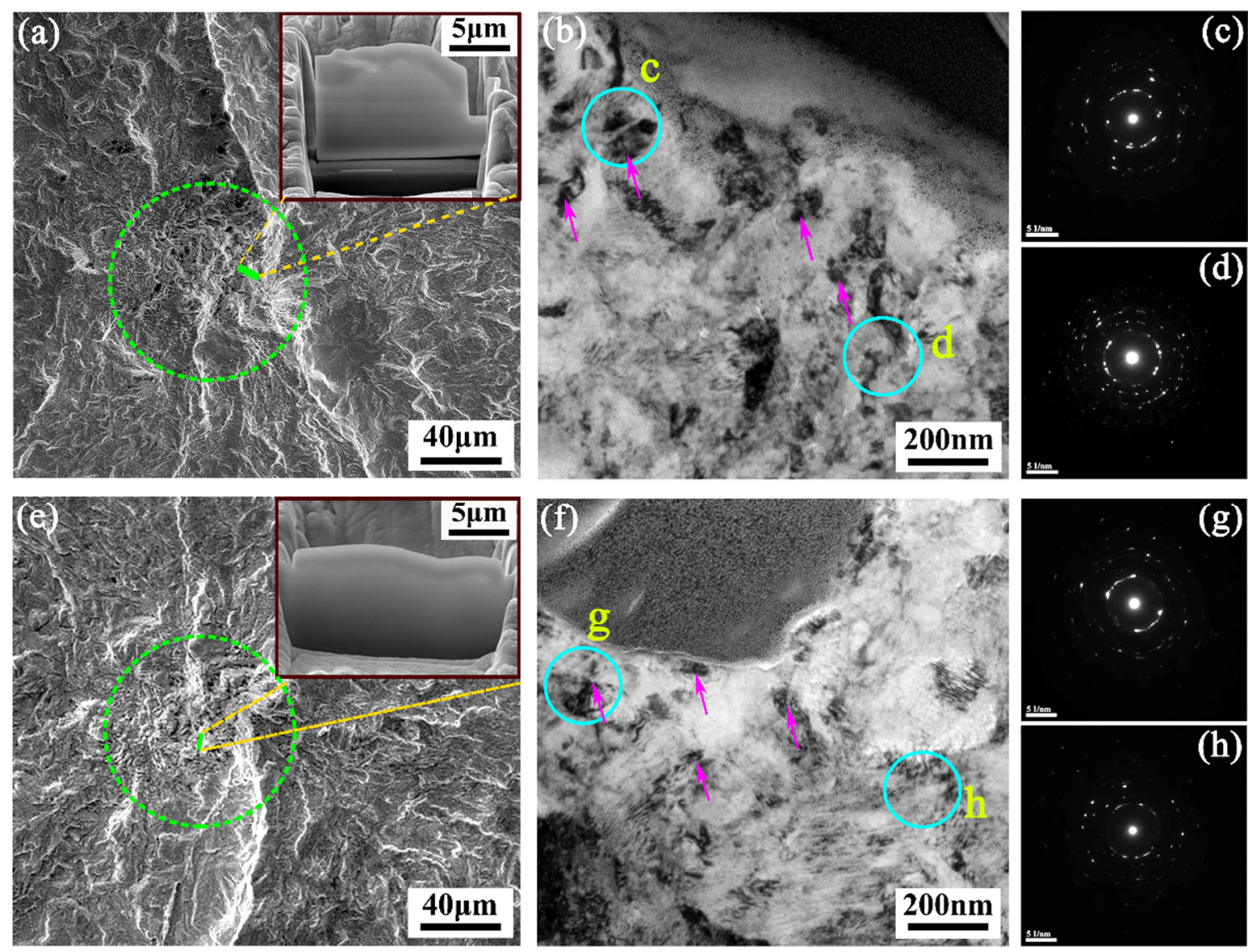

Fig. 6. Microstructural features of samples D1 and D2. (a, e) Fracture surface morphology of failed specimen D1 $\left(R=-1, \sigma_{\mathrm{a}}=550 \mathrm{MPa}, N_{\mathrm{f}}=4.52 \times 10^{7}\right)$ and D2 $\left(R=-1, \sigma_{\mathrm{a}}=450 \mathrm{MPa}, N_{\mathrm{f}}=1.79 \times 10^{9}\right.$ ), showing RA (dotted circle) and sampling location (solid rectangle); (b, f) BFIs of microstructure underneath RA; (c, d, g, h) SAD patterns of discontinuous diffraction circles at the location just underneath RA surface.

layer was detected by SAD method. The SAD examination was continuously performed from the surface of FGA or RA to the inside area. At the location that the related SAD becomes isolated spot patterns, then the point between this detection and the previous one with nanograin diffraction was the boundary of nanograin layer. Thus the thickness of nanograin layer was readily obtained.

\section{Results and discussion}

\subsection{Microstructural features in CIR for high-strength steels}

Fig. 3 presents the TEM observations of microstructural features for samples A1 and B2 cut via FIB in the FGA region of the specimens failed under $R=-1$ and $R=-0.5$, respectively. Fig. $3 \mathrm{a}$ and $\mathrm{b}$ illustrate the fractographic information of failed specimens A1 and B2, in which the inclusions were surrounded by the clear FGA region and the sampling location was shown by a dashed rectangle. Fig. $3 c$ and $d$ show the bright-field images (BFIs) of the microstructure of these two samples, and on the top of these two images a platinum coating layer was deposited to protect the fracture surface. The dark-field imaging mode of TEM was used to scan the entire profile so as to show more information about the microstructure near the fracture surface. Results of dark-field images (DFIs) in observed local areas are shown in Fig. 3e and f, where a thin layer containing many fine particles with tens of nanometers is displayed near the fracture surface, suggesting the formation of nanograins in the FGA region. As shown in Fig. $3 g-j$, discontinuous diffraction rings are presented from SAD examinations of sample profiles, indicating the existence of several grains within the diffraction area of $200 \mathrm{~nm}$ in diameter.

For the purpose of the examination for the cases other than in the
FGA region under negative stress ratios, two TEM samples were prepared from CIR on the fracture surfaces of the specimens failed under positive stress ratios and another two TEM samples were prepared from FiE outside FGA on the fracture surfaces of failed specimens. The associated fracture morphology of failed specimens and sampling locations are shown in Fig. 4.

Fig. $4 a$ and $b$ illustrate the SEM images of crack initiation region for specimens B3 and B4, respectively. Both specimens failed due to fatigue crack initiation from the interior of specimen. It is seen that with the increase of stress ratio, the FGA feature is diminishing as shown in Fig. 4a, even is extinct as shown in Fig. 4b. One TEM sample for each specimen of B3 and B4 was prepared via FIB with the sampling location close to the initiation site as shown by a dashed rectangle, and the microstructural features are shown in Fig. 5a and b, which show that the microstructure on both profiles is original martensite with the SAD patterns being typical isolated spots, meaning no evidence of grain refinement. Note that the SAD patterns on some locations exhibit slightly elongated diffraction spots, which is the result of localized plastic deformation, implying that the plastic deformation at the crack tip can only cause certain extent of deformation in microstructure, but is insufficient to produce nanograins.

For the purpose of further examination for the microstructure features in FiE outside FGA, two TEM samples (A2 and B5) were prepared from the FiE region of the failed specimens in VHCF regime under $R=-1$ and $R=0.3$. The loading conditions of these two specimens are also listed in Table 3. Fig. $4 \mathrm{c}$ and $\mathrm{d}$ are the SEM images of the fracture surface for specimens A2 and B5, in which the sampling locations (marked by solid rectangle) are close to the outer boundary of FiE. Fig. $5 \mathrm{c}$ and d illustrate their microstructural features, which show the microstructure is original martensite. The related isolated spot 

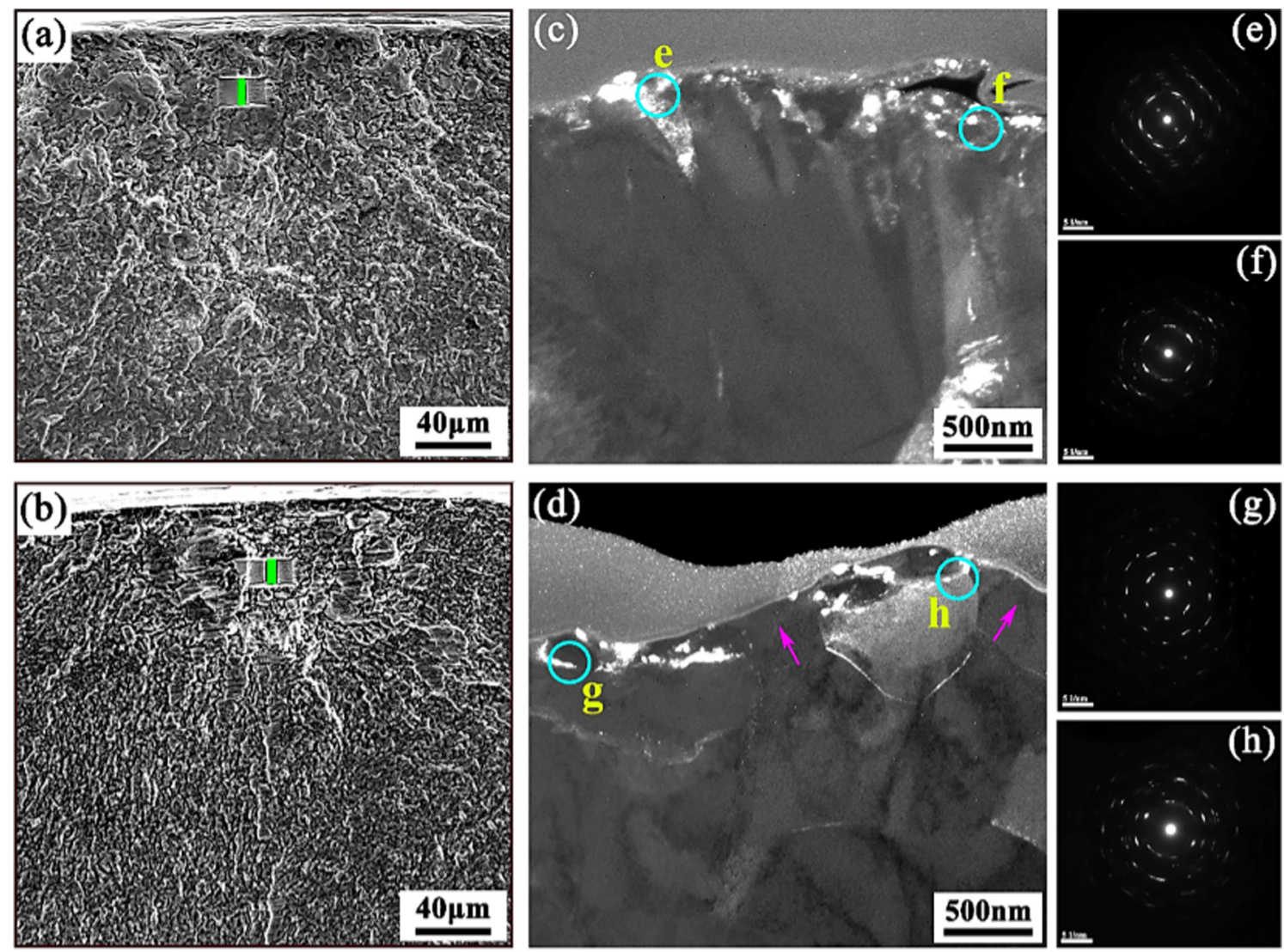

Fig. 7. Microstructural features of samples E1 and E2. (a, b) SEM images of RA region for failed specimens E1 $\left(R=-1, \sigma_{\mathrm{a}}=444 \mathrm{MPa}, N_{\mathrm{f}}=1.06 \times 10^{8}\right)$ and E2 $\left(R=-1, \sigma_{\mathrm{a}}=434 \mathrm{MPa}, N_{\mathrm{f}}=4.51 \times 10^{8}\right)$, marked rectangle being the location for TEM sample cut by FIB; (c, d) DFIs of microstructure underneath RA; (e-h) SAD patterns of discontinuous diffraction circles at the locations (e, $f, g$ and $h$ ) just underneath RA surface.

patterns indicate only one grain within the diffraction area of $200 \mathrm{~nm}$ in diameter. In brief, the results of the microstructure characteristics for samples A2 and B5 indicate that the microstructure underneath the fracture surface in the FiE region outside FGA does not undergo grain refinement, which is likely related to the insufficient pressing during cycling because of the relatively faster crack growth rate in the FiE region outside FGA.

\subsection{Microstructural features in CIR for titanium alloys}

Figs. 6 and 7 present TEM examinations of four TEM samples cut in RA regions of the specimens failed in VHCF regime under $R=-1$ for duplex and equiaxed titanium alloys. Fig. 6a shows the morphology of the crack origin on the fracture surface for specimen D1, where the dashed circle represents the RA region and the solid rectangle represents the sampling location. The upper right corner of Fig. 6a shows the enlargement of TEM sample (D1) extraction via FIB. Fig. 6b shows the highly magnified image near the fracture surface of sample D1, in which many fine particles (pointed by arrows) can be seen. The discontinuous diffraction rings illustrated in Fig. $6 \mathrm{c}$ and d again confirm the existence of nanograins.

In addition, sample D2 was also examined by TEM with SAD detection, and the results similar to sample D1 were obtained and shown in Fig. 6e-h, revealing that microstructure refinement and nanograin formation exist in the RA region of the specimens failed in VHCF regime under negative stress ratio cases for duplex titanium alloys. Similarly, specimens E1 and E2 of equiaxed titanium alloys failed in VHCF regime were selected to prepare TEM samples for the examination of microstructure in RA region. The microstructures in CIR of these two specimens are illustrated in Fig. 7a and b, in which cracks initiate on the surface of the specimen with RA morphology. In fact, this failure type occurred in most specimens that failed in VHCF regime for $\sigma_{\mathrm{m}}=0$ and $\sigma_{\mathrm{m}}>0[33,38]$. The DFIs, as shown in Fig. $7 \mathrm{c}$ and d, reveal a fine granular layer underneath the RA region.

Compared with the results of duplex titanium alloys shown in Fig. 6, the fine granular layer in equiaxed titanium alloys is thinner and discontinuous, as shown in Fig. $7 \mathrm{~d}$ by arrows, which may be attributed to the smaller size of the equiaxed $\alpha$ grains in the titanium alloys with equiaxed microstructure. In general, with the increase of grain size in metallic materials, the resistance to crack growth usually increases, whereas the resistance to crack initiation decreases, and vice versa $[39,40]$. In other words, cracks are easy to initiate but with high resistance to propagate for the materials with large grain size, while opposite trend occurs for the materials with small grain size. Therefore, for equiaxed titanium alloys with small equiaxed $\alpha$ grains, cracks initiated after a long period of cyclic loading and the initiated cracks were easy to propagate in the subsequent period of cyclic loading, which dramatically weakened the interactions between crack surfaces such that the thinner fine granular layer was formed.

Similarly, for the examination of the microstructure in CIR for the titanium specimens failed under the cases of positive stress ratios, two TEM samples were cut via FIB from RA region on the fracture surfaces of specimens D3 $(R=0.5)$ and E3 $(R=0.5)$, as shown in Fig. 8a and b, respectively. The cracks initiated inside the specimen with a large RA of several hundred micrometers in diameter appeared on the fracture surface. Fig. $8 c$ presents the BFI of D3 showing the Pt protection layer and the original equiaxed microstructure. From the BFI of E3 illustrated in Fig. 8d, one can see the original equiaxed microstructure with clear grain boundaries. As presented in Fig. $8 \mathrm{e}-\mathrm{h}$, the SAD patterns of isolated spots indicate that there is only one grain within the diffraction area. It again validates that for the cases of VHCF for titanium alloys under positive stress ratios, the microstructure underneath RA region is 

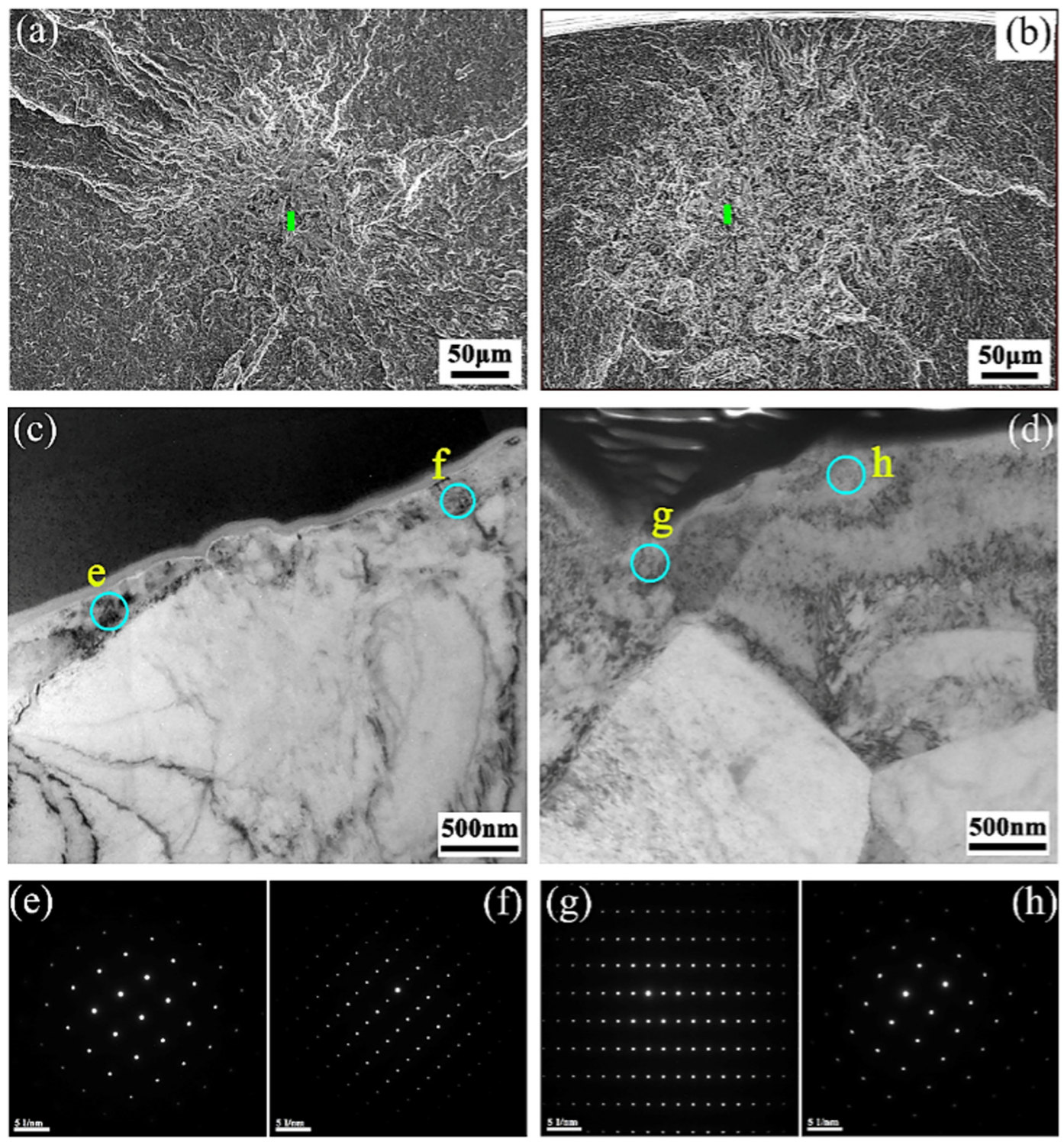

Fig. 8. Microstructure features of specimens D3 and E3. (a) SEM image in CIR of D3 $\left(R=0.5, \sigma_{\mathrm{a}}=240 \mathrm{MPa}, N_{\mathrm{f}}=4.30 \times 10^{7}\right)$; (b) SEM image in CIR of E3 $(R=0.5$, $\sigma_{\mathrm{a}}=148 \mathrm{MPa}, N_{\mathrm{f}}=1.68 \times 10^{8}$ ); in (a) and (b) marked rectangle being the location of TEM sampling; (c) TEM image of microstructure feature underneath CIR for D3; (d) TEM image of microstructure feature underneath CIR for E3; (e-h) SAD patterns of isolated spots at the locations (e, f, $g$ and $h$ ) just underneath fracture surface.
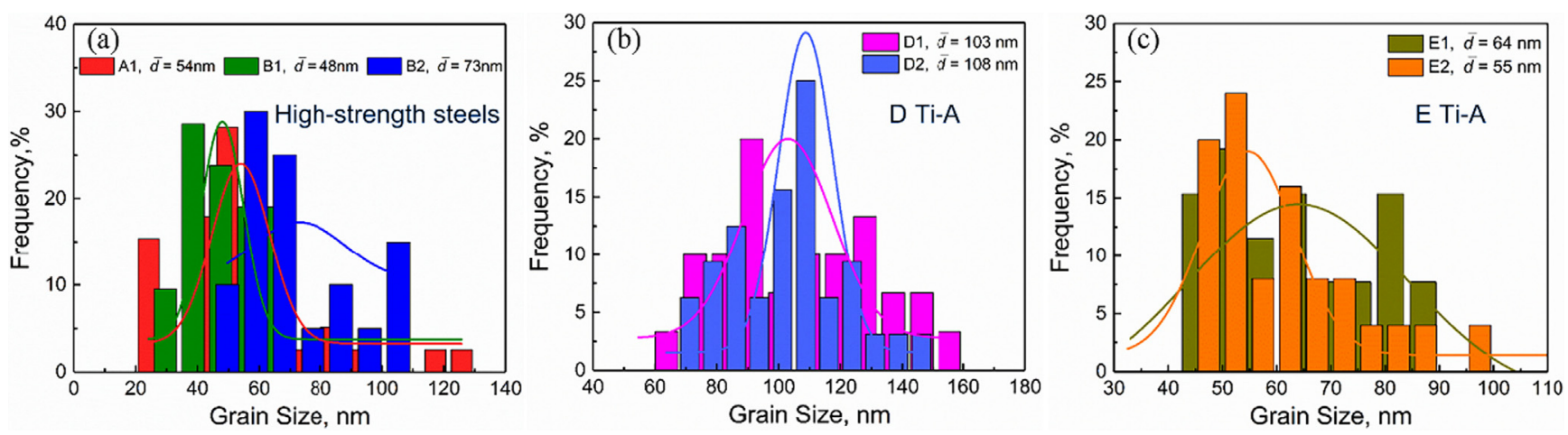

Fig. 9. Distributions of nanograin size just underneath fracture surfaces in CIRs for samples A1, B1 and B2 of high-strength steels (a), for samples D1 and D2 of titanium alloy with duplex microstructure (b), and for samples E1 and E2 of titanium alloy with equiaxed microstructure (c).

not refined for both duplex and equiaxed microstructures of titanium alloys. It should be noted that for these specimens failed under positive stress ratios, crack surfaces become free surfaces since the applied loading condition is tension-tension, i.e., the compressive stress is zero. As described in the NCP model [31], compressive stress (which will induce localized shear deformation) is a dominant factor to the 

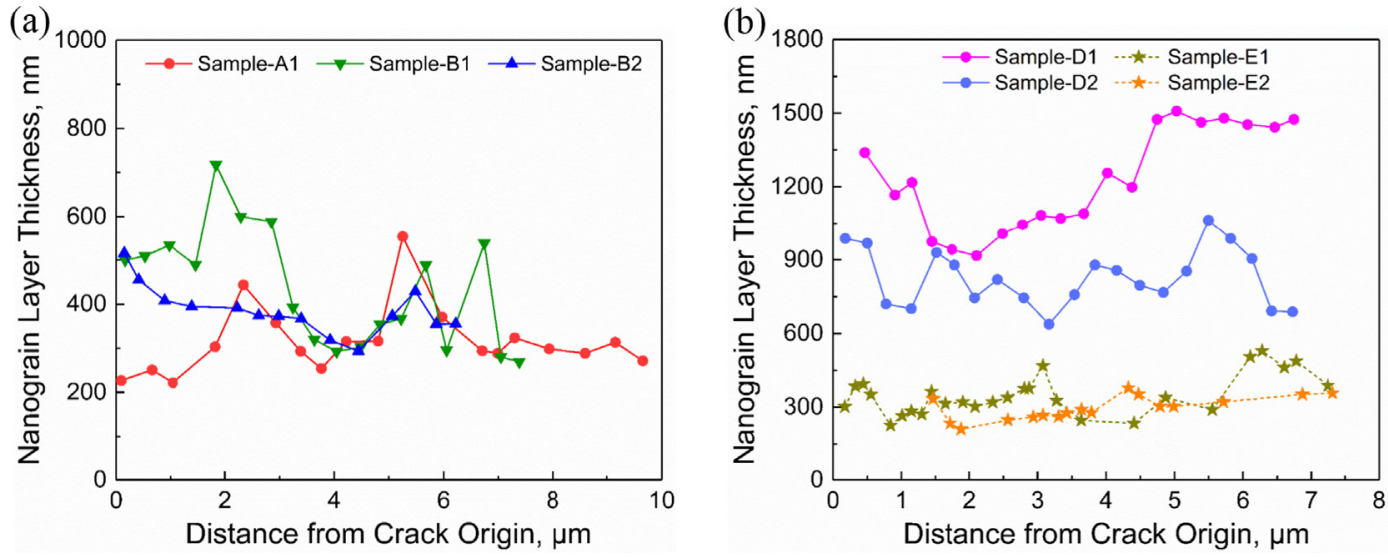

Fig. 10. Variations of nanograin layer thickness with the distance away from crack origin for high-strength steels (a), and titanium alloys (b).

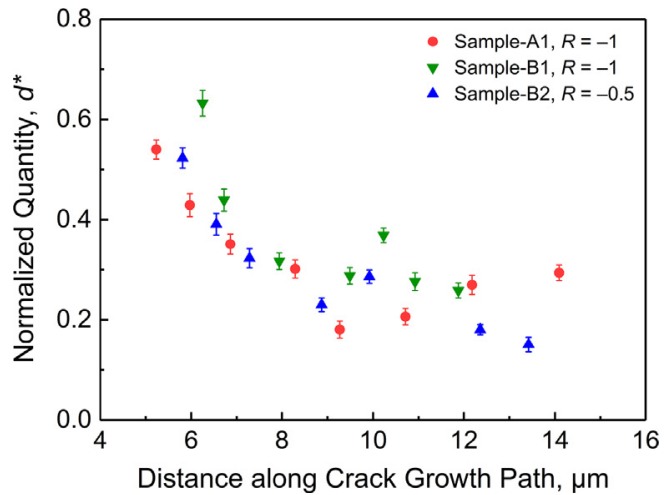

Fig. 11. Distribution of normalized quantity $d^{*}$ versus crack growth path for TEM samples of high-strength steels.

formation of nanograins underneath CIR in VHCF of metallic materials. Thus, nanograins are less possible to be produced in the tension-tension loading condition.

\subsection{Distributions of nanograin size and thickness of nanograin layer}

The nanograin size and the thickness of the nanograin layer for the samples of high-strength steels and titanium alloys were measured to analyze the sensitivity of microstructure to the formation of nanograins, and the results are shown in Figs. 9 and 10. For the high-strength steels, it is seen from Fig. 9a that the grain size ranges from 20 to $130 \mathrm{~nm}$, and the average equivalent diameters are $54 \mathrm{~nm}, 48 \mathrm{~nm}$ and $73 \mathrm{~nm}$ for samples A1, B1 and B2, respectively. It is interesting that the average nanograin size for the case of $R=-1$ is about $50 \mathrm{~nm}$ (A1 and B1), and that for the case of $R=-0.5$ is $73 \mathrm{~nm}$ (B2), suggesting that for the case of fully reversed cycling $(R=-1)$, the process of grain refinement in the FGA region is more remarkable thanks to the more severely contacting actions between crack surfaces. For the titanium alloys, the difference in grain size distribution and average size is evident. The grain size range is between 60 and $160 \mathrm{~nm}$ with the average value of $110 \mathrm{~nm}$ for duplex microstructure (Fig. 9b), and the range is between 40 and $100 \mathrm{~nm}$ with the average value of $60 \mathrm{~nm}$ for equiaxed microstructure (Fig. 9c), which is in relation to the larger size of original $\alpha$ grains for the former. Furthermore, the thickness variation of the nanograin layer along the crack growth path was measured for the samples and the results are shown in Fig. 10. It is seen that the thickness ranges from 300 to $600 \mathrm{~nm}$ for the high-strength steels. For titanium alloys, the thickness of the nanograin layer is between 200 and $500 \mathrm{~nm}$ for equiaxed microstructure and is between 700 and $1500 \mathrm{~nm}$ for duplex microstructure, which is again attributed to the difference in the size of original $\alpha$ grains discussed previously. In addition, the thickness of the nanograin layer varies largely along the crack growth path, implying the substantial influence of the microstructure on the formation of local nanograins. Note that the nanograin size of B1 is slightly finer than that of A1 (Fig. 9), and the nanograin layer thickness of B1 is slightly thicker than that of A1 (Fig. 10), which is in relation to the higher stress amplitude and longer loading cycles for A1.

\subsection{Quantitative description of grain size underneath FGA and RA}

The phenomenon of microstructure refinement and nanograin appearance underneath FGA and RA is a vital clue to understand the formation mechanism of FGA and RA during VHCF regime of metallic materials. The results presented in previous sections have confirmed the existence of nanograins in FGA and RA for negative stress ratio cases, whereas the detail of nanograin size distribution and the effect of external loading conditions on such distribution are still unclear.

As an effective approach for analyzing the microstructure of materials, SAD technique can be utilized to detect microstructure characteristics objectively. According to the diffraction mechanism [37], an SAD pattern will be a series of rings if the detected area contains many grains with great difference in orientation, and with the increase of the number of grains, namely more fine grains, the diffraction rings will become more continuous. Therefore, we propose a normalized quantity $d^{*}$ to quantitatively describe the nanograin size distribution in FGA and RA regions:

$d^{*}=\frac{l}{l_{0}}$

where $l_{0}$ is the perimeter of a completely continuous diffraction ring associated with a given crystal plane family, and $l$ is the total length of a discontinuous ring measured in experiments. It is clear that the larger value of $d^{*}$ represents the smaller grain size in the detected area.

In view of this, a number of discontinuous diffraction rings associated with $\left\{\begin{array}{lll}1 & 1 & 0\end{array}\right\}$ planes for samples A1, B1 and B2 were measured, and the results described by $d^{*}$ are illustrated in Fig. 11. The value of $d^{*}$ notably decreases along the crack growth path, implying that the nanograin size gradually increases with the propagation of cracks, which is likely resulted from the gradually-reduced pressing actions between crack surfaces. Moreover, the datum points of B1 are evidently higher than those of A1 and B2, suggesting that greater contacting actions between crack surfaces and longer loading cycles promote the grain refinement in CIR.

Similarly, many discontinuous diffraction rings associated with \{0111 $\}$ planes for samples D1 and D2 were measured, and the results described by $d^{*}$ are illustrated in Fig. 12a. Further, two specific 2-D plots corresponding to Fig. 12a are drawn as shown in Fig. 12b and c so as to have a plane view of the distributions of $d^{*}$ value as a function of crack growth path and crack depth. Fig. 12b shows that the value of $d^{*}$ 

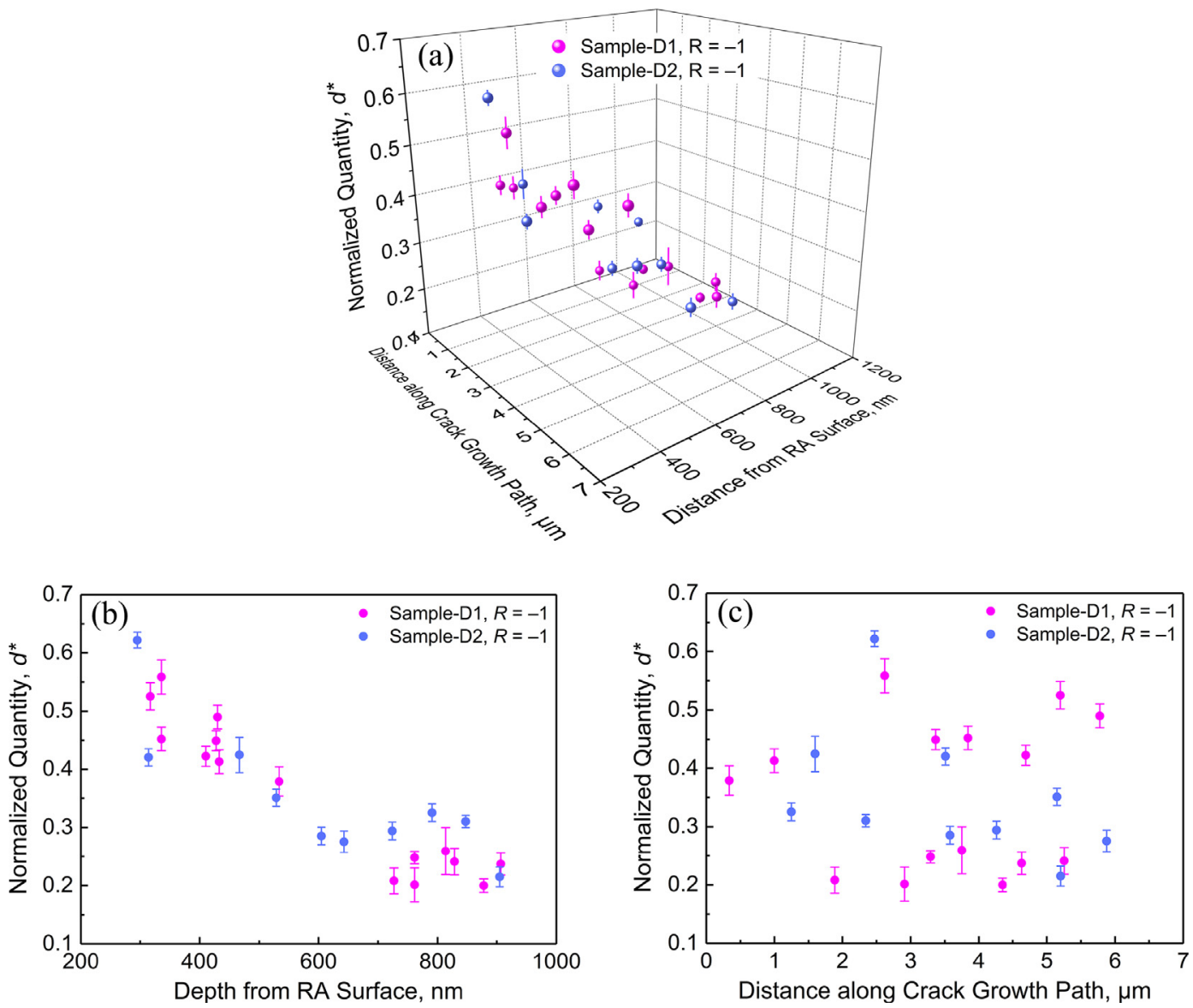

Fig. 12. Distribution of normalized quantity $d^{*}$ for TEM samples of duplex titanium alloys. (a) 3-D plot; (b) 2-D plot showing the projection distribution of $d^{*}$ along crack depth direction; (c) 2-D plot showing the projection distribution of $d^{*}$ along crack path direction.

decreases evidently along the direction of crack depth, meaning the gradual increase of grain size, which indicates that grains become finer when they are closer to fracture surface. However, the variation of value $d^{*}$ is insensitive to the distance along the crack growth path within crack initiation region, as shown in Fig. 12c, which may be ascribed to the cleavage mode of crack initiation in RA region. For samples E1 and E2, the effective data are insufficient to construct the size distribution due to the related nanograin layers being thin and intermittent, and thus $d^{*}$ is not applicable for these two samples. Note that the nanograin size of B1 is slightly finer than that of A1 (Fig. 9), and the nanograin layer thickness of $\mathrm{B} 1$ is slightly thicker than that of $\mathrm{A} 1$ (Fig. 10), which is in relation to the higher stress amplitude and longer loading cycles for A1. Note also that the nanograin thickness of B2 is similar to that of $\mathrm{B} 1$, although the stress ratio of the former is -0.5 against the $R$ value of -1 for the latter, which may be ascribed to the much longer failure cycles for B2, thus to compensate the difference in the negative part of loading actions.

In general, the microstructure refinement and nanograin formation in the crack initiation region for high-strength alloys subjected to VHCF under negative stress ratios will be affected by the value of stress ratio and stress amplitude or loading cycles. For instance, compared with the case of $R=-0.5$, the case of $R=-1$ will have relatively finer nanograins and thicker nanograin layer, and the longer loading cycles will produce finer nanograins and thicker nanograin layer. The results of Figs. 9 and 11 reflect more or less such trends. However, the measuring methods of nanograin size are different for Figs. 9 and 11. The data of nanogrian size in Fig. 9 were measured by dark-field images, but for Fig. 11, the data of nanograin size were obtained based on SAD patterns, which presents the average value of nanograin size in the selected area with the diameter of $200 \mathrm{~nm}$. Thus, this may cause some inconsistencies between the two figures.

\subsection{NCP process to form nanograins}

As aforementioned, nanograins only exist in the FGA and the RA regions of the specimens failed under negative stress ratios. According to the accumulation of experimental results on high-strength steels and titanium alloys, there are two issues should be addressed. First, there is a remarkable difference in the morphology of CIR between highstrength steels and titanium alloys. For high-strength steels, the morphology in FGA is directly related to the existence of nanograins. But for titanium alloys, there is no direct relation between the morphology in RA and the formation of nanograins. This can be explained by the fact that the RA morphology of titanium alloys is caused by the coalescence of cleavage facets regardless of the state of stress ratio and microstructure. Also, it can be seen from the comparison of experimental results between high-strength steels and titanium alloys that the inclusion is not a necessary condition to form nanograins. Therefore, a new schematic of the NCP model is depicted as shown in Fig. 13, illustrating the initiation and growth of the crack, and the formation of the nanograin layer.

Fig. 13a illustrates the fatigue process of high-strength steels. First, the cracks initiate at the interface between the inclusion and the matrix under cyclic loading. Next, with the early propagation of the cracks, nanograins are gradually formed at crack wake due to the contacting action between crack surfaces. Then, with the continuation of crack propagation and the pressing between crack surfaces, a nanograin layer forms on the crack surfaces. Similarly, the fatigue processes of titanium alloys are presented in Fig. 13b and c. In addition to internal crack initiation in a few cases (Fig. 13b), the surface defect induced crack 
(a)
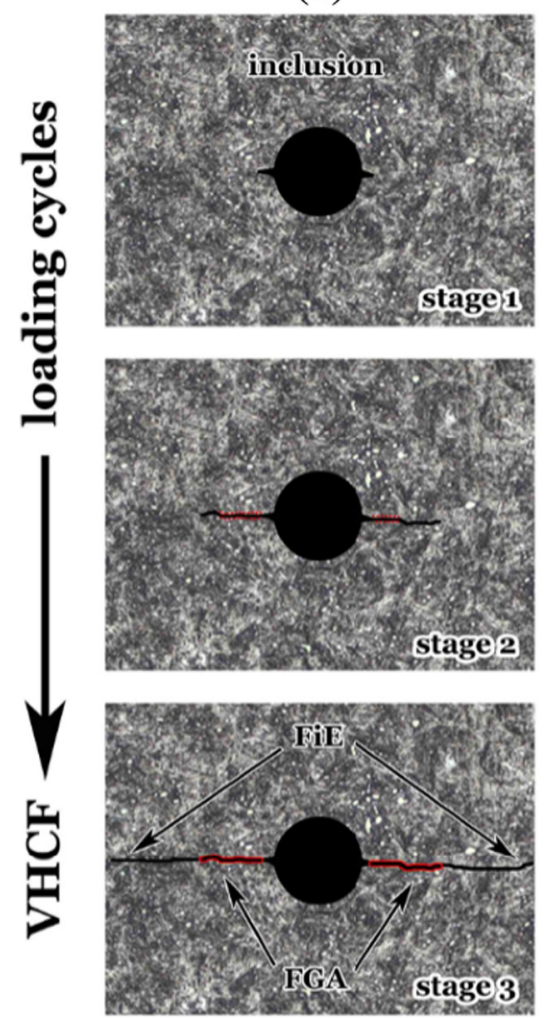

crack: (b)
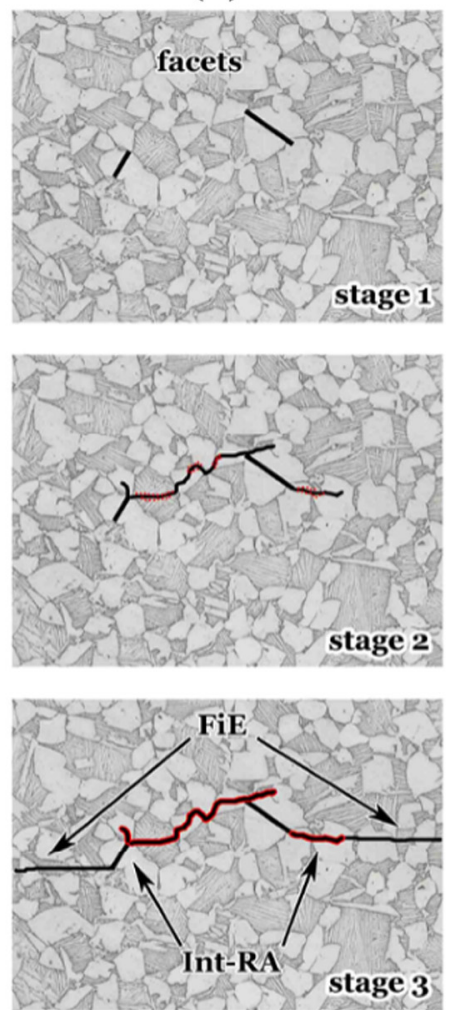

(c)
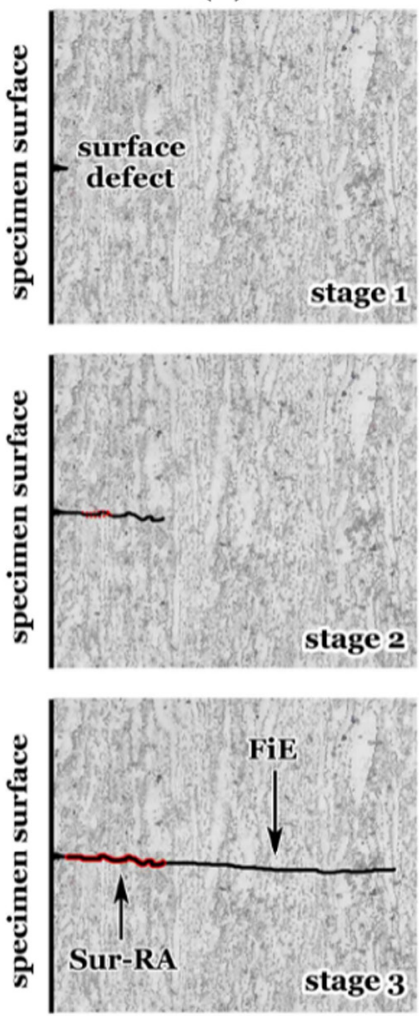

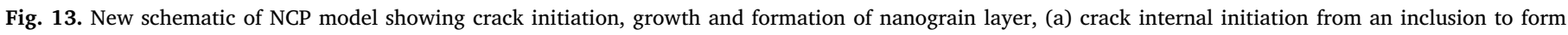

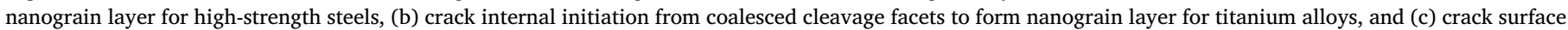
initiation from surface defects to form nanograin layer for titanium alloys.

initiation commonly becomes overwhelming for the cases with negative stress ratios (Fig. 13c). Under cyclic loading, the facet cracks keep propagating and some of the adjacent cracks coalesce, and then nanograins may form. When the coalesced facets form a main crack in the cluster, the tested specimen will soon become failure.

\section{Conclusions}

In this paper, the detailed characteristics of the microstructures in CIRs of a number of failed specimens in VHCF regime for two highstrength metallic materials (steels and titanium alloys) are systematically investigated. The conclusions are as follows:

(1) The FGA region of the high-strength steels under negative stress ratios is a nanograin layer. The nanograin size ranges from 20 to $130 \mathrm{~nm}$ with the average size of $50 \mathrm{~nm}$ for the case of $R=-1$ and $73 \mathrm{~nm}$ for the case of $R=-0.5$, and the nanograin layer thickness ranges from 300 to $600 \mathrm{~nm}$.

(2) The RA region of the titanium alloys under negative stress ratios is a nanograin layer. The nanograin size ranges from 40 to $100 \mathrm{~nm}$ with the average value of $60 \mathrm{~nm}$ for equiaxed microstructure, and ranges from 60 to $160 \mathrm{~nm}$ with the average of $110 \mathrm{~nm}$ for duplex microstructure. The nanograin layer thickness ranges from 200 to $500 \mathrm{~nm}$ for equiaxed microstructure and from 700 to $1500 \mathrm{~nm}$ for duplex microstructure. The difference in nanograin size and nanograin layer thickness is mainly attributed to the difference in the size of original $\alpha$ grains.

(3) A normalized quantity $d^{*}$ based on the electron diffraction mechanism is proposed to quantitatively describe the distribution of grain size underneath FGA and RA. The decrease of $d^{*}$ value along the crack growth path for high-strength steels suggests that the nanograin size increases with the crack growth, which is associated with the gradually-reduced contacting actions between crack surfaces.

(4) The NCP process dominates the formation of nanograin layer in CIR underneath FGA and RA surface for negative stress ratio cases, with larger contacting actions (higher contact pressure and longer loading cycles) between crack surfaces promoting the grain refinement. The plastic deformation at crack tip can cause certain extent of deformation in microstructure, but is insufficient to produce nanograins.

(5) Based on the microstructure examinations on high-strength steels and titanium alloys, a new schematic of the NCP model was depicted to describe the NCP process that causes the microstructure refinement.

\section{Declaration of Competing Interest}

The authors declare that they have no known competing financial interests or personal relationships that could have appeared to influence the work reported in this paper.

\section{Acknowledgements}

The authors would like to thank the financial support from the National Natural Science Foundation of China (11932020, 11572325) and from the Strategic Priority Research Program of the Chinese Academy of Sciences (XDB22040503 and XDB22020201).

\section{References}

[1] Stanzl-Tschegg SE. Fracture mechanical characterization of the initiation and 
growth of interior fatigue cracks. Fatigue Fract Eng Mater Struct 2017;40:1741-51.

[2] Mayer H. Recent developments in ultrasonic fatigue. Fatigue Fract Eng Mater Struct 2016;39:3-29.

[3] Sakai T, Nakagawa A, Oguma N, Nakamura Y, Ueno A, Kikuchi S, et al. A review on fatigue fracture modes of structural metallic materials in very high cycle regime. Int J Fatigue 2016;93:339-51.

[4] Hong Y, Sun C. The nature and the mechanism of crack initiation and early growth for very-high-cycle fatigue of metallic materials - An overview. Theor Appl Fract Mech 2017;92:331-50.

[5] Jeddi D, Palin-Luc T. A review about the effects of structural and operational factors on the gigacycle fatigue of steels. Fatigue Fract Eng Mater Struct 2018;41:969-90.

[6] Tanaka K, Akiniwa Y. Fatigue crack propagation behaviour derived from $\mathrm{S} \pm \mathrm{N}$ data in veryhigh cycle regime. Fatigue Fract Eng Mater Struct 2002;25:775-84.

[7] Mayer H, Haydn W, Schuller R, Issler S, Furtner B, Bacherhochst M. Very high cycle fatigue properties of bainitic high carbon-chromium steel. Int J Fatigue 2009;31:242-9.

[8] Shiozawa K, Hasegawa T, Kashiwagi Y, Lu L. Very high cycle fatigue properties of bearing steel under axial loading condition. Int J Fatigue 2009;31:880-8.

[9] Lei Z, Hong Y, Xie J, Sun C, Zhao A. Effects of inclusion size and location on veryhigh-cycle fatigue behavior for high strength steels. Mater Sci Eng, A 2012;558:234-41.

[10] Sakai T, Takeda M, Shiozawa K, Ochi Y, Nakajima M, Nakamura T, et al. Experimental reconfirmation of characteristic $S-N$ property for high carbon chromium bearing steel in wide life region in rotating bending. J Soc Mater Sci, Jap 2000;49:779-85.

[11] Nakamura T, Oguma H, Shinohara Y. The effect of vacuum-like environment inside sub-surface fatigue crack on the formation of ODA fracture surface in high strength steel. Procedia Eng 2010;2:2121-9.

[12] Ogawa T, Stanzl-Tschegg SE, Schönbauer BM. A fracture mechanics approach to interior fatigue crack growth in the very high cycle regime. Eng Fract Mech 2014; 115:241-54.

[13] Hong Y, Lei Z, Sun C, Zhao A. Propensities of crack interior initiation and early growth for very-high-cycle fatigue of high strength steels. Int J Fatigue 2014;58:144-51.

[14] Hu Y, Sun C, Hong Y. Crack growth rates and microstructure feature of initiation region for very-high-cycle fatigue of a high-strength steel. Fatigue Fract Eng Mater Struct 2018;41:1717-32.

[15] Zhao A, Xie J, Sun C, Lei Z, Hong Y. Prediction of threshold value for FGA formation. Mater Sci Eng, A 2011;528:6872-7.

[16] Shiozawa K, Lu L. Very high-cycle fatigue behaviour of shot-peened high-carbonchromium bearing steel. Fatigue Fract Eng Mater Struct 2002;25:813-22.

[17] Sakai T, Sato Y, Oguma N. Characteristic S-N properties of high-carbon-chromiumbearing steel under axial loading in long-life fatigue. Fatigue Fract Eng Mater Struct 2002;25:765-73.

[18] Banerjee A, Prusty BG. Fatigue and fracture behaviour of austenitic-martensitic high carbon steel under high cycle fatigue: An experimental investigation. Mater Sci Eng, A 2019;749:79-88.

[19] Tanaka K, Akiniwa Y. Fatigue crack propagation behaviour derived from S-N data in very high cycle regime. Fatigue Fract Eng Mater Struct 2002;25:775-84.

[20] Murakami Yu, Nomoto T, Ueda T, Murakami Ya. On the mechanism of fatigue failure in the superlong life regime ( $\mathrm{N}>10^{7}$ cycles), Part II: a fractographic investigation. Fatigue Fract Eng Mater Struct 2000;23:903-10.

[21] Liu X, Sun C, Hong Y. Effects of stress ratio on high-cycle and very-high-cycle fatigue behavior of a Ti-6Al-4V alloy. Mater Sci Eng, A 2015;622:228-35.

[22] Liu X, Sun C, Hong Y. Faceted crack initiation characteristics for high-cycle and very-high-cycle fatigue of a titanium alloy under different stress ratios. Int J Fatigue 2016;92:434-41.

[23] Cao F, Chandran KSR. The role of crack origin size and early stage crack growth on high cycle fatigue of powder metallurgy Ti-6Al-4V alloy. Int J Fatigue 2017; 102:48-58.

[24] Li W, Zhao H, Nehila A, Zhang Z, Sakai T. Very high cycle fatigue of TC4 titanium alloy under variable stress ratio: Failure mechanism and life prediction. Int J Fatigue 2017;104:342-54.

[25] Su H, Liu X, Sun C, Hong Y. Nanograin layer formation at crack initiation region for very-high-cycle fatigue of a Ti-6Al-4V alloy. Fatigue Fract Eng Mater Struct 2017;40:979-93.

[26] Sakai T. Review and prospects for current studies on very high cycle fatigue of metallic materials for machine structural use. J Solid Mech Mater Eng 2009;3:425-39.

[27] Grad P, Reuscher B, Brodyanski A, Kopnarski M, Kerscher E. Mechanism of fatigue crack initiation and propagation in the very high cycle fatigue regime of highstrength steels. Scripta Mater 2012;67:838-41.

[28] Spriestersbach D, Kerscher E. The role of local plasticity during very high cycle fatigue crack initiation in high-strength steels. Int J Fatigue 2018:111:93-100.

[29] Kovacs S, Beck T, Singheiser L. Influence of mean stresses on fatigue life and damage of a turbine blade steel in the VHCF-regime. Int J Fatigue 2013;49:90-9.

[30] Oguma H, Nakamura T. Fatigue crack propagation properties of Ti-6Al-4V in vacuum environments. Int J Fatigue 2013;50:89-93.

[31] Hong Y, Liu X, Lei Z, Sun C. The formation mechanism of characteristic region at crack initiation for very-high-cycle fatigue of high-strength steels. Int J Fatigue 2016;89:108-18.

[32] Jiang Q, Sun C, Liu X, Hong Y. Very-high-cycle fatigue behavior of a structural steel with and without induced surface defects. Int J Fatigue 2016;93:352-62.

[33] Pan X, Su H, Sun C, Hong Y. The behavior of crack initiation and early growth in high-cycle and very-high-cycle fatigue regimes for a titanium alloy. Int J Fatigue 2018;115:67-78.

[34] Pineau A, Forest S. Effects of inclusions on the very high cycle fatigue behaviour of steels. Fatigue Fract Eng Mater Struct 2017;40:1694-707.

[35] Stäcker C, Sander M. Experimental, analytical and numerical analyses of constant and variable amplitude loadings in the very high cycle fatigue regime. Theor Appl Fract Mech 2017;92:394-409.

[36] Ritz F, Stäcker C, Beck T, Sander M. FGA formation mechanism for X10CrNiMoV12 2-2 and 34CrNiMo6 for constant and variable amplitude tests under the influence of applied mean loads. Fatigue Fract Eng Mater Struct 2018;41:1576-87.

[37] Williams DB, Carter CB. Transmission Electron Microscopy: A Textbook for Materials Science. second ed. Springer; 2009.

[38] Pan X, Hong Y. High-cycle and very-high-cycle fatigue behaviour of a titanium alloy with equiaxed microstructure under different mean stresses. Fatigue Fract Eng Mater Struct 2019;42:1950-64.

[39] Suresh S. Fatigue of materials. second ed. Cambridge University Press; 1998.

[40] Yin D, Liu H, Chen Y, Yi D, Wang B, Wang B, et al. Effect of grain size on fatiguecrack growth in 2524 aluminium alloy. Int J Fatigue 2016;84:9-16. 